\title{
Early Years
}

\section{Professional development within the Effective Early Learning Programme: a contribution to a participatory and context-sensitive approach to ECEC evaluation}

\section{Sara Barros Araújo}

To cite this article: Sara Barros Araújo (2015) Professional development within the Effective Early Learning Programme: a contribution to a participatory and context-sensitive approach to ECEC evaluation, Early Years, 35:3, 249-259, DOI: 10.1080/09575146.2014.995599

To link to this article: https://doi.org/10.1080/09575146.2014.995599

央 Published online: 20 Jan 2015.

Submit your article to this journal $₫$

山ll Article views: 472

View Crossmark data \lceil 


\title{
Professional development within the Effective Early Learning Programme: a contribution to a participatory and context-sensitive approach to ECEC evaluation
}

\author{
Sara Barros Araújo* \\ School of Education, Polytechnic Institute of Porto, Porto, Portugal \\ (Received 2 July 2014; accepted 13 November 2014)

\begin{abstract}
This paper aims to describe and analyse a case study on professional development that was centred on the Effective Early Learning (EEL) Programme. This process was a part of a larger dissemination project of the EEL programme nationwide, designed to train specialised facilitators at a local level who could, in turn, support the professional development of their peers. From a theoretical stance, it focuses on a democratic and participatory approach to the evaluation and development of quality in ECEC contexts. The study involved the participation of 12 pre-school teachers and a specialised trainer. Results show perceived effects of the process of staff development on professional learning at the level of observation skills, reflection-on-action and critical insertion. Also, the participants recognised that experimentation in practice contexts and shared reflection were the most meaningful and facilitative strategies in their learning.
\end{abstract}

Keywords: evaluation and development of quality; Effective Early Learning Programme; participatory frameworks; professional development

\section{Introduction}

In Portugal, evaluation and assessment in pre-school education started to receive more attention during the 1990s due to several shifts at the level of educational politics and the expansion of the pre-school education network. In 1997, the curricular guidelines for pre-school education from the ministry of education (DEB - ME 1997) identified the need for intentional professional action, and considered evaluation as a core process in order to guarantee intentionality in pre-school contexts. In spite of these important initiatives, this field continued to be undervalued in the contexts of practice. This was for several reasons, namely the poorness of teacher training and the lack of research, including the use of programs and/or procedures for the evaluation and development of quality. As a consequence, the evaluation culture remained poor with, on the one hand, a lack of systematic and coherent approaches to ECEC evaluation, visible in the scarcity of evaluation practices and, on the other hand, the acritical application of methods used in primary education, with a strict focus on outcomes. The search for alternatives that could support a change in this scenario led to the adoption of the Effective Early Learning (EEL) Programme (Bertram and Pascal 2009; Pascal et al. 1995) and to a project to contextualise and

*Email: saraujo@ese.ipp.pt 
disseminate this programme in Portugal. The study presented in this article constituted a part of this project.

\section{Evaluation and development of quality in ECEC contexts: the quest for a democratic, participatory and context-sensitive approach}

For many years, evaluation and assessment in ECEC contexts was considered under a positivist umbrella, centred on external control and a dichotomy between the evaluator and the object of evaluation (Guba and Lincoln 1989). According to Moss and Dahlberg (2008), this positivistic and instrumental discourse is highly influenced by values such as certainty, mastery, linear progress, predetermined outcomes, objectivity, universality, stability and closure. Fleer (2002) considers that these discourses and practices reduce complexity to what can be compared. The emergence of a constructivist paradigm (Guba and Lincoln 1989) brought new ways of conceiving and practising evaluation in ECEC contexts, valuing participants, processes and meanings. A technology of distance (Moss and Dahlberg 2008) that underlies evaluation in a positivist paradigm has been challenged as failing to meet the diverse, complex and situated needs of children, professionals, families and institutions. A participatory and formative approach to evaluation has been advocated as a more sensitive and responsive alternative which acknowledges the idiosyncrasies of people and contexts.

The EEL programme originates in a democratic and participatory approach to the evaluation and development of quality in ECEC contexts (Pascal and Bertram 1997). EEL considers that evaluation and development of quality are centrally influenced by the people who daily live and experience ECEC contexts, namely practitioners, children and families. Quality is recognised as subjective and polysemous (Oliveira-Formosinho 2009a). This means that quality is not dependent on monolithic and prescribed external criteria, but constitutes a contextualised construction, open to the subjective and pluriform meanings of local participants. Thus, quality is defined by the shared reflections and agreements between these participants; it is validated and scrutinised by those who are closer to the learning experiences that are being evaluated (Pascal and Bertram 1997), taking reflexive attached commitment as a principle (Formosinho and Formosinho 2012, 602).

In the EEL programme, participation is intrinsically linked to empowering people and to the recognition of agency as a core personal, professional and organisational right and resource. As stated by Pascal, agency is a cascade fed by democratic and participatory governance (2003, 11). Thus, EEL emphasises collaboration synergies between participants within the processes of evaluation and transformation of quality, creating the opportunity for their perspectives to be valued, and assuming partnership and co-ownership as paramount.

The EEL programme endorses critical reflection and action by participants, and can serve, borrowing the words of Freire (2005), their critical insertion. For the Brazilian pedagogue, critical insertion implies an objectification of reality, i.e. an objective recognition of reality and the motivation to act upon it, with a transformative intention. Freire (2005) argues that the more people unravel the objective and challenge reality upon which their action must focus, the more they are critically inserted in that reality. Critical insertion is an important condition for conscious, rather than naïve, action upon reality (Freire 1979). This also constitutes an important premise in EEL's proposal, considering that the programme draws an intrinsic connection between evaluation and development of quality, with a clear emphasis 
on evaluation that is oriented towards transformation. What becomes clear is the situated nature of the EEL programme and its integration in a contextual paradigm for quality analysis (Oliveira-Formosinho 2009a). EEL is considered to be a contextsensitive and context-responsive programme, deeply rooted in the idiosyncrasies of different contexts and oriented towards contextualised meaning-making (PaciniKetchabaw and Pence 2011), in a permanent trade with the empirical world (Morin 1990, 105). In fact, the focus on the spatial and temporal loci of the institutions, activity rooms, groups and persons - daily life in itself - is a seminal and cross-cutting condition for evaluation and transformation.

\section{Professional development within EEL: a case study in the School of Education of Porto}

In Portugal, the EEL programme took the name of Desenvolvendo a Qualidade em Parcerias (Developing Quality in Partnerships). Its contextualisation to Portuguese reality was begun by the Childhood Project and Childhood Association, with the support of the Aga Khan Foundation and Calouste Gulbenkian Foundation. In 2007, the Portuguese Ministry of Education decided to make this framework available nationwide. From 2007 to 2009, a team of university teachers, researchers and professionals from pre-school institutions, coming from several districts of the country, underwent a process of intense training in the EEL programme. The process encompassed experimenting in the use of EEL in pre-school institutions, and research, as well as the production of materials, namely a translated and adapted EEL manual (Bertram and Pascal 2009) and a book that included 15 case studies resulting from the process (Oliveira-Formosinho 2009b). In 2010-2011, the Portuguese Ministry of Education launched and supported the second phase of this project, i.e. the dissemination of the EEL programme nationwide, through the training of trainers who could act at local level.

A group of participants who took part in the first phase of the project agreed to integrate this new phase of dissemination, with the support of a scientific coordinator and a team from the Ministry of Education. This group met periodically in order to plan, discuss, monitor and evaluate the formative experiences. This article intends to present and analyse the professional development process of one of these groups, located in the School of Education at the Institute Polytechnic of Porto. The choice of a case study was linked to the need to study the particularities and complexities of this specific case, in order to construct an experiential understanding (Stake 1995), through descriptive, heuristic and inductive processes (Merriam 1990).

This constituted a pioneering experience in the development of evaluation frameworks for ECEC contexts in Portugal. It was felt that immersive case studies would provide a platform for the construction of knowledge that could benefit future participants in staff development related to the evaluation and transformation of quality in ECEC contexts.

\section{Method}

\section{Research aims}

The study presented three aims: (i) to develop a process of training of trainers taking the EEL programme; (ii) to understand the effects of participation in that process on professional learning; (iii) to understand the processes and strategies that participants perceived as more critical for professional learning. 


\section{Participants}

The process of training of trainers involved the participation of 12 pre-school teachers and one specialised facilitator. The pre-school teachers were invited to take part in the process, in accordance with some pre-determined criteria. These criteria were: (i) motivation to be involved in the staff development process and willingness to become an EEL trainer; (ii) professional training in early childhood education; (iii) professional experience in early childhood education; (iv) experience in the professional development of pre-school teachers (namely, as internship supervisor); (v) research experience in evaluation. Although not all of the criteria had to be met, the choice of participants should consider as many of the criteria as possible. From the 12 selected participants, all met the first three criteria, nine met the fourth criteria and six met the last criteria.

The facilitator of this group was involved for several years in professional development and research activities based on the EEL framework and was involved in the first phase of EEL's introduction in Portugal.

\section{Techniques of data collection}

The data-set encompassed pre-school teachers' written reflections and field notes from the facilitator. Each pre-school teacher was asked to write three reflections on the experience of applying the pedagogical observation instruments which are central to the EEL programme (adult engagement, child involvement and target) and a final reflection, considering the overall experience. This produced a total of 48 written reflections. The written field notes of the facilitator were centred on the training process and integrated descriptive and interpretative components. Written reflections and field notes were used simultaneously to monitor and regulate the process, and also to construct knowledge about it. The data-set was subjected to content analysis and data triangulation processes (Denzin 1978), considering that triangulation, according to Denzin and Lincoln (2000), by displaying multiple, refracted realities simultaneously, adds rigour and complexity to the research, strengthening its trustworthiness (Lincoln and Guba 2000).

\section{Procedures and contents}

The module on professional development comprised $108 \mathrm{~h}$ of participation, based on a project methodology that included classroom sessions and autonomous work carried out in contexts of practice, aiming at trying out the observation instruments which constitute a core part of this framework.

In terms of content the module encompassed: (i) the historical and theoretical context of EEL's framework, namely its integration in an ecological perspective of evaluation in early childhood education; (ii) methodological aspects of EEL's assessment process; (iii) EEL's observation instruments: adults' engagement, children's involvement, target observations and interviews (especially, interviews with children). Recognising the importance of two of these instruments in order to fully understand results, observation of adults' engagement and observation of children's involvement, a brief overview of each of them is presented: 


\section{Observation of adults' engagement}

The observation of adults' engagement is based on the premise that the quality of adults' intervention constitutes a critical factor in the quality of learning experienced by the child (Bertram and Pascal 2006). It is based on Ferre Laevers's observations on teaching style and centres around the micro analysis of the interactions between the adult and children (Laevers, Bogaerts, and Moons 1997). Laevers proposes three dimensions that serve as the basis for observing adults' actions: sensitivity towards the needs and perceptions of children, the stimulating nature of interventions and the creation of opportunities for autonomy. Bertram proposed the term engagement as a catalyst for these dimensions, referring to the qualities that describe the nature of educational relations and the adult's capacity to motivate, extend, promote and involve children in learning processes (Pascal and Bertram 1997). The authors of EEL assume that the informed use of this instrument, by teams characterised by openness and relational and professional honesty, will have positive effects on the quality of adult-child interaction, on the empowerment of professionals and the promotion of work relations open to reflection and change, in processes of professional development (Bertram and Pascal 2006, 2009).

\section{Observation of children's involvement}

The concept of involvement was introduced by Ferre Laevers within the experiential education approach. According to Laevers, involvement results from an interactive process of high complexity involving the pre-school teacher, the infrastructure, the group and the child. Involvement is: (i) recognised by concentration and persistence; (ii) characterised by motivation, interest, openness to stimuli, satisfaction and energy; (iii) influenced by exploratory drive and individual needs; and (iv) signals that development is taking place (Laevers 1994b). The observation of involvement allows for an evaluation centred on the processes in which children engage and is a central indicator that reflects the nature and characteristics of the educational environment (context) and is reflected in children's learning (outcomes) (Laevers 1994a).

The group started with an analysis of concepts and their operationalisation, followed by making observations following the directions in the EEL manual (observation and analysis of videotaped pedagogical situations, in pairs and individually, sharing and reflecting within the group). The next step was in-context observation carried out through direct observation, analysis of videotaped pedagogical situations, written reflections about the experimentation process and sharing/debate within the group.

Ethical concerns included the ongoing informed consent of participants and assurances of confidentiality. Also, special attention was given to such aspects as positionality, polivocality, self-reflexivity, reciprocity and benefit (Lincoln and Guba 2000), which are important when research is conceived as an ethical endeavour.

\section{Perceived effects of participation at the level of professional learning}

The analysis of participants' perspectives revealed effects in three domains: (i) observation skills (observation of context, processes and results); (ii) reflection-onaction; and (iii) critical insertion. 


\section{Effects at the level of observation skills (context, processes, results)}

Participation in the EEL module was perceived as having positive effects at the level of participants' observation skills. Observation skills had not been emphasised in their initial and complementary training, which led to difficulties in their practices. Participants stated that the module contributed to a more intentional and grounded type of observation, to the improvement of the organisation of the observation process and to the construction of interpretations of the significance of the aspects that were observed. The words of a pre-school teacher were quite clear about this:

It allowed me to reflect about my practices and it was an opportunity in what concerns the difficult and complex task of observing. This skill is very neglected in initial training and is almost non-existent in complementary training but, at the same time, is essential in a pre-school teacher practice. EEL Programme is an excellent process at this level because its instruments allow us to add rigour to our observation. I've always felt difficulties in knowing what to observe. Now, however, our observation is guided to specific areas, arranged according to indicators that allow me, not only to synthesize data, but also to attribute a meaning to it. In parallel, this new skill triggered a new way to organize my pedagogical documentation and that was an enormous asset in my professional development. (Written narrative of pre-school teacher G.C.)

Pre-school teachers were unanimous in recognising that participation in the EEL module improved their observation, register and assessment skills, which were assumed as relevant in the monitoring of practices. In the words of one of the participants:

I understood that observation demands time, training and learning on the part of professionals (...) But I had also the clear perception that observation is the key to learn more about the child, about our own practices and about the several dimensions of the learning environment. When a pre-school teacher observes a child, she is collecting important data that will help to know better each child, to understand how she thinks and feels, becoming more prepared to make decisions that will contribute to her progress and development. By examining their own actions in this process, professionals will monitor their practices, allowing them to better respond to the child's needs, interests and developmental changes, creating new opportunities and challenges. (Written narrative of pre-school teacher L.B.)

The association between professional practices and learning opportunities for children, recognised as symbiotic, became more salient. Also, there was a growing awareness that the creation of learning opportunities for adults is a necessary condition for the creation of generative learning opportunities for children.

\section{Effects at the level of reflection-on-action}

The pre-school teachers also stressed the relevance of their participation in the module at the level of self-assessment, emphasising the role of EEL as a facilitator of reflection. Reflection became a process that was no longer intuitive but carried out within a specific framework. Because of the reflective strategies that were adopted, the process represented an opportunity for pre-school teachers to question their previous practices concerning evaluation, namely at the level of instruments and intentionality. This excerpt from a written reflection illustrates this point:

This process led me to question my search for child assessment checklists in order to evaluate the child, when what was important was to evaluate my practices, which reveal the way to work well with children. I've found dozens of checklists to assess 
children, but none to evaluate the pre-school teachers' practices, as if learning failures were centred on the child. This module strengthened the idea that more important than assessing the child is evaluating the learning opportunities that my practice offers to the child. (Written narrative of pre-school teacher L.P.)

From the standpoint of observation and evaluation, a change was noticed in the loci of these processes: they were no longer exclusively centred on results, but started to focus on practices. It is also possible to assert that the locus of causality and responsibility was displaced, incorporating centrally the pre-school teachers' practices. This seemed a very positive movement towards a more conscious and responsible practice. This displacement could also be seen, in a more generic way, as the beginning of a shift from a transmissive evaluation, centred on the discovery of facts and the certification of learning, towards a participatory evaluation, centred on the processes and achievements of children in their meaningful learning, implicating all actors, centrally assuming observation in real context and favouring connections to daily practices (Oliveira-Formosinho and Araújo 2011).

The EEL module, which was developed in spirals of action and reflection, was considered meaningful for pracitioners' growing capacity to reflect and problematise. At this level, processes such as oral and written reflection about experimentation in the practice contexts were revealed to be facilitators, which allowed for the construction of meanings about the aspects that were presented and analysed in the classroom. At this level, the heuristic-hermeneutic analysis that was carried out with observation instruments was considered quite relevant by the participants, allowing data to be perceived, not only as a numerical representation, but as having a powerful pedagogical consistency. In fact, the process of critical reflection that was promoted, individually and collectively, around the specificities that were observed was much more important than the numerical data. This 'deconstruction of numbers' and the contextualised analysis of the experiences of children and adults were considered very important inputs to understand and rethink practices.

\section{Effects at the level of critical insertion}

Another process that seemed to be promoted by the participation in the module was professionals' critical insertion, a concept used by Freire (2005) to signify an objective recognition of reality and the motivation to act upon it, with transformative intention. In this particular case, critical insertion is paramount, considering that EEL describes an intrinsic nexus between quality evaluation and quality development. EEL advocates an evaluation that is dynamic and oriented towards transformation. The advantage of generating cycles of action and reflection during the process once again became clear, favouring a more complex and rigorous understanding of the contexts and the role of pre-school teachers. In the words of a participant:

In my perspective, this [the use of EEL, in kindergarten rooms] depends only on the will to make a journey of self-knowledge and personal and professional growth. This is not always an easy or painless journey. Whether in your personal or professional life, choosing reflection, evaluation and transformation implies almost every time finding failures and needs that aren't always 'nice' to recognise. Then, it's necessary to become aware that this is a necessary stage in development and have in mind that evaluation has a formative nature and is not a value judgement. (Written narrative of pre-school teacher L.C.) 
This pre-school teacher emphasised the importance of being open to a journey of self-knowledge and personal and professional growth, not always recognised as easy or painless, but permeated by an understanding of the regulatory and formative nature of evaluation and of its non-judgemental nature. This understanding was, in the perception of participants, critical, because it opened the way for sharing and reflection not dominated by the fear of being judged, but accepted in an atmosphere of openness, trust and motivation towards change.

The process of critical insertion can be seen to represent a certain disruption with previous ways of understanding and practising evaluation, and constituted an intrinsic condition for transformation. Indeed, transformation should be based on a rigorous and critical understanding of reality, and not on spontaneous or voluntarist outbursts. One of the participants used Plato's Cave Allegory to better communicate her experience throughout the process, at a professional and personal level:

If one asks me to give my opinion about this formative process I would say that it resembles Plato's Cave Allegory. This comparison occurs to me frequently. It seems that before knowing this framework I was like the prisoners inside the cave: I only saw the shadows of things. The EEL Programme allowed me, not only to see with more clarity, but also to be able to reflect in a more rigorous manner about my practice and the context in which I work. (Written narrative of pre-school teacher G.C.)

This can be considered a very rich excerpt from the standpoint of understanding this experience, because it recognises EEL as a framework that promotes reflection, critical awareness, rigour and clarity, which are relevant foundations for transformation and change.

\section{Meaningfulness of the module's processes and strategies in professional learning}

Considering the third aim of the study - to understand the processes and strategies that participants perceived as more critical for professional learning - the opinions expressed by the participants revealed the importance of: (i) experimentation in practice contexts; (ii) shared reflection.

\section{Experimentation in contexts of practice}

Professionals considered context-based experimentation as very meaningful. Its value was recognised at the level of the contextualisation and understanding of theoretical concepts and in the incentive to engage in reflection-on-action. In fact, pre-school teachers emphasised that the appropriation of the framework was easier when it was carried out in an ecological context because it was possible to verify all the potential of the observation instruments, and because doubts and questioning emerged in a more visible way and difficulties were identified. According to one of the participants:

One of the most useful aspects in this module was working in context. It allowed us to experiment with our group, inside our educational reality $(\ldots)$ this experimentation becomes indispensable for the pre-school teacher, because it supports her/him in a constant reflection-on-action, considering the child's involvement and their learning. (Written narrative of pre-school teacher F.A.) 
As an example, and concentrating on the observation of the child's involvement, experimentation in the pre-school rooms facilitated the understanding of the contextual nature of children's involvement, allowing the pre-school teachers to trace connections, for example, between the quality of the physical environment and children's levels of involvement. The symbiosis between adults' engagement and children's involvement also seemed to be understood. Also, difficulties identified by pre-school teachers in their practice (e.g. difficulties in stimulating all children in mixed-age groups) were perceived as influencing children's involvement. According to pre-school teachers, context-based observation facilitated the exercise of empathy with children, which they found necessary in the observation of involvement.

The pre-school teachers stressed the importance of the mediation of a specialised facilitator throughout the experimentation process and the need to maintain this support, in order to consolidate learning. This need for support was reinforced by all the participants.

\section{The importance of shared reflection}

Another aspect that was made explicit by the participants was the fact that the group functioned as an important facilitator of the learning process, a catalyst for change (Araújo 2012, 512), with a relevant role at the level of support, clarification, articulation between theory and practice, questioning and reflection. There was a consensus that shared reflection was an important condition to guarantee, in the words of one of the pre-school teachers, the commitment to rigour. An excerpt of the written narratives of the participants illustrates the positive and empowering perception of the group regarding the collaborative and shared nature of the process:

For me, the contribution of all the members who took part in this module enriched the knowledge of each one of us, helped us to reflect on the process that took place in different educational contexts and on the difficulties found in each experimentation. During sessions I felt more support, interaction and confrontation of ideas than I had felt for a long time. This facilitated and strengthened the capacity in praxis of each participant and turned the group more motivated to develop quality. (Written narrative of preschool teacher M.G.)

Participants reinforced the importance of the interpersonal and collaborative nature of reflection, and of what we could describe, borrowing Morin's words, as a lived solidarity (1990) within the group. This ethos did not deny, however, the benefits of confrontation and dissent in professional learning.

\section{Final considerations: the need to strengthen an evaluation culture in pre-school education}

In times of severe bureaucratic constraints and control, EEL continues to represent a democratic and participatory alternative to reductionist external approaches to the evaluation of ECEC contexts. EEL denies a technology of distance (Moss and Dahlberg 2008) associated with this process, advocating instead that rigour is strongly rooted in attachment, proximity and self-vigilance, i.e. in reflexive attached commitment as a principle (Formosinho and Formosinho 2012, 602). This means that local actors are not excluded or peripheral participants, but are centrally relevant for the evaluation and development of quality in ECEC contexts. 
As stated throughout the paper, all participants perceived clear benefits from their participation in the EEL module at the level of professional learning, also recognising its adequacy and utility for professional practice. They also anticipated several possibilities for using the EEL framework that are associated with urgent needs in Portugal: (i) initial and continuous training of early childhood education teachers; (ii) transformation of quality in pre-school institutions and activity rooms; (iii) formal evaluation of teachers. All of these constitute important arenas for the construction of an evaluation culture in pre-school education. In fact, as stressed by Oliveira-Formosinho (2009a), EEL can be an important tool for pedagogical documentation that could help to make educational processes and achievements visible, creating an internal evaluation culture based on reflection about daily life, in the realm of a democratic process of accountability. In a more generic way, EEL was also perceived as an important contribution to a necessary strengthening of professional culture in pre-school education.

\section{References}

Araújo, S. B. 2012. "Researching Change: A Praxeological Case Study on Toddlers' Educational Contexts." European Early Childhood Education Research Journal 20 (4): 505517. doi:10.1080/1350293X.2012.737706.

Bertram, T., and C. Pascal. 2006. The Baby Effective Early Learning Programme: Improving Quality in Early Childhood Settings for Children from Birth to Three Years. Birmingham: Amber Publishing.

Bertram, T., and C. Pascal. 2009. Manual DQP - Desenvolvendo a Qualidade em Parcerias [Manual DQP - Developing Quality in Partnerships]. Lisboa: Ministério da Educação Direcção Geral de Inovação e Desenvolvimento Curricular.

Denzin, N. 1978. The Research Act: A Theoretical Introduction to Sociological Methods. New York: McGraw Hill.

Denzin, N. K., and Y. S. Lincoln. 2000. "Introduction: The Discipline and Practice of Qualitative Research." In Handbook of Qualitative Research, edited by N. K. Denzin and Y. S. Lincoln, 1-28. Thousand Oaks, CA: Sage.

Departamento de Educação Básica - Ministério da Educação. 1997. Orientações Curriculares para a Educação Pré-Escolar [Curricular Guidelines for Pre-school Education]. Lisboa: Departamento de Educação Básica - Ministério da Educação.

Fleer, M. 2002. "Sociocultural Assessment in Early Years Education: Myth or Reality?" International Journal of Early Years Education 10 (2): 105-120. doi:10.1080/ 09669760220141999.

Formosinho, J., and J. Formosinho. 2012. "Towards a Social Science of the Social: The Contribution of Praxeological Research." European Early Childhood Education Research Journal 20 (4): 591-606. doi:10.1080/1350293X.2012.737237.

Freire, P. 1979. Conscientização: teoria e prática da libertação - Uma introdução ao pensamento de Paulo Freire [Conscientização: Theory and Practice of Liberation - An Introduction to the Thinking of Paulo Freire]. São Paulo: Cortez \& Moraes.

Freire, P. 2005. Pedagogia do oprimido [Pedagogy of the Opressed]. Rio de Janeiro: Editora Paz e Terra.

Guba, E., and Y. Lincoln. 1989. Fourth Generation Evaluation. Newbury Park, CA: Sage Publications.

Laevers, F. 1994a. The Leuven Involvement Scale for Young Children LIS-YC. Manual and Video Tape, Experiential Education Series, N. 1. Leuven: Centre for Experiential Education.

Laevers, F. 1994b. "The Innovative Project Experiential Education and the Definition of Quality in Education." In Defining and Assessing Quality in Early Childhood Education, edited by F. Laevers, 159-172. Leuven: Leuven University Press.

Laevers, F., M. Bogaerts, and J. Moons. 1997. Experiential Education at Work: A Setting with 5 Years Old - Manual. Leuven: Centre for Experiential Education - University of Leuven. 
Lincoln, Y. S., and E. G. Guba. 2000. "Paradigmatic Controversies, Contradictions, and Emerging Confluences." In Handbook of Qualitative Research, edited by N. K. Denzin and Y. S. Lincoln, 163-188. Thousand Oaks, CA: Sage.

Merriam, S. B. 1990. Case Study Research in Education. Oxford: University Press.

Morin, E. 1990. Introduction á la pensée complexe [Introduction to Complex Thinking]. Paris: ESF Éditeur.

Moss, P., and G. Dahlberg. 2008. "Beyond Quality in Early Childhood Education and Care Languages of Evaluation." New Zealand Journal of Teachers' Work 5 (1): 3-12.

Oliveira-Formosinho, J. 2009a. "A avaliação da qualidade como garantia do impacto da provisão na Educação de Infầncia." [Evaluation of Quality as a Guarantee of Impact in the Provision of Early Childhood Education]. In Manual DQP-Desenvolvendo a Qualidade em Parcerias [Manual DQP-Developing Quality in Partnerships], edited by T. Bertram, and C. Pascal, 9-23. Lisboa: DGIDC.

Oliveira-Formosinho, Julia, org. 2009b. Desenvolvendo a Qualidade em Parcerias: Estudos de caso [Developing Quality in Partnerships: Case Studies]. Lisboa: DGIDC.

Oliveira-Formosinho, J., and S. B. Araújo. 2011. "Early Education for Diversity: Starting from Birth." European Early Childhood Education Research Journal 19 (2): 221-233. doi:10.1080/1350293X.2011.574410.

Pacini-Ketchabaw, V., and A. Pence. 2011. "The Postmodern Curriculum: Making Space for Historically and Politically Situated Understandings." Australasian Journal of Early Childhood 36 (1): 4-8.

Pascal, C. 2003. "Effective Early Learning: An Act of Practical Theory." European Early Childhood Education Research Journal 11 (2): 7-28. doi:10.1080/13502930385209141.

Pascal, C., and T. Bertram. 1997. Effective Early Learning: Case Studies in Improvement. London: Paul Chapman Publishing.

Pascal, C., A. Bertram, F. Ramsden, J. Georgeson, M. Saunders, and C. Mould. 1995. Evaluating and Developing Quality in Early Childhood Settings: A Professional Development Programme. Worcester: Amber Publishing.

Stake, R. 1995. The Art of Case Study Research. Thousand Oaks, CA: Sage. 